\title{
High hopes for cannabinoid agonists in the treatment of rheumatic diseases
}

\author{
Caroline A Staunton ${ }^{1}$, Ali Mobasheri ${ }^{2,3,4,5}$ and Richard Barrett-Jolley ${ }^{1,2^{*}}$
}

\begin{abstract}
There are two well-characterised isoforms of cannabinoid receptor; $C B_{1}$ and $C B_{2}$ and of these $C B_{2}$ is under active investigation as a potential target for treatment of the chronic pain associated with widespread and intractable joint diseases osteoarthritis and rheumatoid arthritis. The recent report by Fukuda et al (BMC Musculoskelet Disord $15: 275,2014$ ) in BMC Musculoskeletal Disorders investigates the efficacy of a selective $C_{2}$ agonist, JW133, in both in vitro and in vivo models of rheumatoid arthritis and provides encouraging data. The report shows that JW133 inhibits expression of the CCL2 cytokine, osteoclastogenesis and reduces histological indicators of joint degeneration. Each of these could potentially contribute to beneficial analgesic effects in a therapeutic context.
\end{abstract}

Keywords: Cannabinoids, Cannabis, Chronic pain, Dorsal root ganglia, lon channels, Fibroblast-like synoviocytes (FLS), JW133, Osteoarthritis (OA), Rheumatoid Arthritis (RA)

\section{Background}

The cannabinoids are a family of compounds from the plant Cannabis sativa L. (sativa meaning useful) the well-known being the alkaloid $\Delta^{9}$ tetrahydrocannabinol (THC). Recent years have seen an explosion of complexity in the field of cannabinoid pharmacology. It was discovered quite early that there were potentially a number of active constituents of the plant and there were two clearly distinguishable receptor subtypes $\mathrm{CB}_{1}$ and $\mathrm{CB}_{2}[1,2]$, but more recently this list is looking likely to grow, as former so called orphan G-protein coupled receptors such as GPR55 [3] and potentially GPR18 [4] emerge as receptors for cannabinoids. Furthermore there are well-known ion channels, such as TRPV1 and other proteins such as nuclear peroxisome proliferator-activated receptors (PPAR's) that appear to be modulated by cannabinoids [5]. This already multifaceted story has started to now become even more complex with the identification of not just agonists, but antagonists, allosteric modulators [6] and inverse agonists [7]. The most basic summary of cannabinoid pharmacology indicates that $\mathrm{CB}_{1}$ is generally

\footnotetext{
* Correspondence: RBJ@liv.ac.uk

'Department of Musculoskeletal Biology, Institute of Ageing and Chronic Disease, University of Liverpool, Liverpool L69 3GA, United Kingdom

${ }^{2}$ The D-BOARD European Consortium for Biomarker Discovery, School of Veterinary Medicine, Faculty of Health and Medical Sciences, University of Surrey, Duke of Kent Building, Guildford, Surrey GU2 7XH, UK

Full list of author information is available at the end of the article
}

located to neurones and the CNS [8] and $\mathrm{CB}_{2}$ located elsewhere [1]. Naturally every rule has its exceptions. For example many assume that $\mathrm{CB}_{2}$ receptors are not expressed in brain, this is in fact inaccurate; although expression of this receptor can be induced in immune cells, they are resident in brain microglia or simply infiltrating immune cells [9]. Cannabinoid receptors are therefore present in the inflammatory pain pathway at both the peripheral and central (spinal and supraspinal) levels [10]. The expression of $\mathrm{CB}_{1}$ is largely restricted to neuronal cells and in particular those neuronal cells responsible for nociceptive processing within the brain and the peripheral nervous system [8]. $\mathrm{CB}_{2}$ receptor expression is predominantly restricted to immune cells including glia and in the context of this editorial it was originally identified in macrophages $[1,11]$ (See Figure 1). It is probably too early to be too categorical about the other emerging subtypes.

Enthusiasm for cannabinoids as medicines seems to go through phases. Firstly, it was thought of as a recreational drug; then potential medicinal benefits emerged and later as the widespread (approaching pleiotropic) actions were identified it started to appear as if their actions were too widespread to biomedical and pharmaceutical utility. The discovery of a positive interaction between cannabinoid ligands and TRPV1 was particularly disappointing, since TRPV1 is a widespread mediator of joint nociception [14]. 


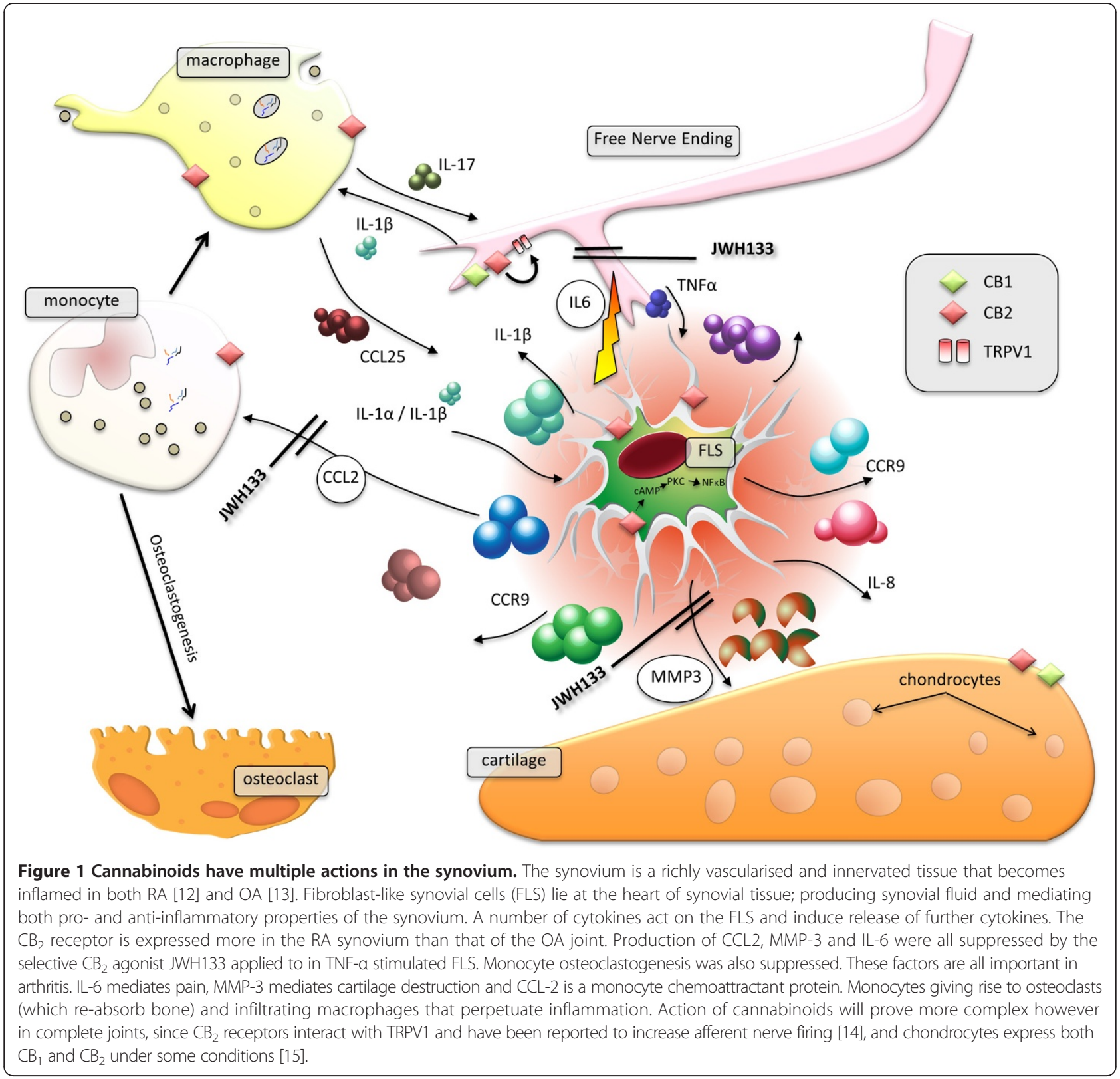

Selective ligands are now emerging however and hope is returning to the field of medicinal cannabinoid research.

\section{Main text}

The separation of $\mathrm{CB}_{1}$ and $\mathrm{CB}_{2}$ implies that activation of $\mathrm{CB}_{2}$ will be without psychotropic effects and so considerable efforts have gone into selective ligands for this receptor in particular. A series of analogues were produced by Huffman et al [16] and the paper published by Fukuda et al 2014 in BMC Musculoskeletal Disorders [17] explores one of these JWH133 in the context of rheumatology.

Joint pharmacology is an often-overlooked area of research, despite the clear need for novel treatments for a range of disorders. The overall burden of musculoskeletal disease to society is enormous with the majority of elderly people affected. A large part of this is arthritis; the two most common subtypes of which are rheumatoid arthritis (RA), an autoimmune disease that typically progresses to all joints and osteoarthritis (OA), a condition with multiple and less well-defined aetiologies. Although the global prevalence of RA itself is modest $(0.24 \%)$, the disease is severe and protracted and is therefore a major contributor to pain and disability accounting for approximately 5 million disability-adjusted life years (DALYs) in 2010 [18]. In $2002 \mathrm{WHO}$ ranked OA and RA as the first and second largest individual causes of "years lived with disability" (YLD) [19] and the more recent and comprehensive 2010 Global Burden of Disease study placed musculoskeletal 
disorders as the largest contributor (23.2\%) to YLD in the world apart from mental health conditions [20].

Synovitis is increasingly viewed as a pathogenic factor in arthritic diseases. In OA, synovitis is common $[13,21,22]$, but in RA it is the central component [23,24]. A number of potential treatments are available to reduce pain generally (NSAIDs or paracetamol), or inflammation in RA and OA however control of rheumatic pain specifically is difficult. Latest treatments for RA include biological interventions that interfere with TNF- $\alpha$ signalling and the recent discovery of interactions between cartilage and subchondral bone [25] mediated by NGF and the FGF family of peptides has brought some excitement to treatment of OA in particular [26]. Both sprifermin (human recombinant FGF-18) and tanezumab (anti-NFG monoclonal antibody) [27] are both showing promise. Non-peptide drugs are also frequently advantageous over peptides due to their (often) greater ease of preparation and usage. The synovium contains sensory nerve endings however and a clear source of pain; probably in both RA and OA. Whilst a considerable amount is known about the pharmacology of chondrocytes [28], considerably less is known about equally important synovial cells. In fact the synovium as a whole has received less attention that the other joint tissues, partly due to its relative inaccessibility and fragility in a typical rodent model. Interestingly, however, the major cellular component of the normal synovium is type B or fibroblast-like synoviocyte (FLS) and these can be isolated from humans [29] and larger animals [30], but even relatively straightforwardly, from rodents [31]. A well-established contributor of joint inflammation is the infiltration of synovial macrophages. Macrophages express $\mathrm{CB}_{2}$ receptors, and additionally, cannabinoid receptors are expressed on neuronal cells. Therefore there is scope for a complex pattern of cannabinoid interactions within the synovium and surrounding joint tissue. Fukoda et al [17] now test the efficacy of the 200 fold selective $\mathrm{CB}_{2}$ agonist JWH133 against both FLS inflammation and the murine collagen type II (CII)-induced arthritis (CIA) model of RA. They find widespread and encouraging results. In vitro, they culture FLS from RA patients and show that FLS produce IL-6, MMP-3, and CCL2 (also known as monocyte chemotactic protein, MCP-1) in response to TNF- $\alpha$ stimulation. This is interesting at a number of levels; IL-6 is known to induce pain $[32,33]$. MMP-3 has roles in matrix turn over and may diffuse from the synovium into cartilage in parallel to MMP-13 [34]. CCL2 is known to be elevated in RA samples [35], this is a chemokine often referred to as MCP1 and is involved in the recruitment of monocytes, macrophages, T-cells and dendritic cells to the sites of inflammation. Fukoda et al [17] also showed how the promising JWH133 was able to inhibit CCL2 expression. There were other observations too. For example, JWH133 inhibited markers of osteoclastogenesis and this too could have implications for preservation of bone loss in RA. Osteoclastogenesis is a multi-complex procedure that includes many stages, and each one of which is a potential therapeutic target in OA [36] and many other diseases including osteoporosis [37]. This is an additional promising role for JWH133 and fits nicely with the observation $\mathrm{CB}_{2}$-deficient mice develop osteoporosis with age [37] and that JWH133 attenuated pain behaviours in a rat model of OA [38]. Fukuda et al observed [17] an over-all reduction in arthritic "score" in CIA mice injected with JWH133 compared to controls, again enforcing the potential for JWH133.

\section{Conclusions}

Musculoskeletal biology has been in need of a selective $\mathrm{CB}_{2}$ agonist in arthritic models. The apparent beneficial effects reported here are comparatively mild, but could be synergistic to each other with benefits in terms of reduced pain, reduced inflammatory activity and reduced osteoclastogenesis of infiltrating macrophages. This is the first report of positive effects of a selective $\mathrm{CB}_{2}$ agonist in the CIA model. Although the effect was mild, optimization of dosage and/or treatment protocol might enhance the effect. Perhaps, even more selective $\mathrm{CB}_{2}$ agonists might solve this problem. JWH133 is approximately 200 fold selective $\left(\mathrm{CB}_{2} / \mathrm{CB}_{1}\right)$ [16] and the future may see selectivity orders of magnitude greater than this in the near future. So this study is early; but very encouraging, providing yet more evidence [39] that the therapeutic potential of cannabis extracts, and its analogues are enormous.

\section{Abbreviations \\ CIA: Collagen type II (CII)-induced arthritis; DALY: Disability-adjusted life years; FLS: Fibroblast-like synoviocytes; MMP: Matrix metalloproteinase; MCP- \\ 1: Monocyte chemotactic protein; NSAIDs: Non-steroidal anti-inflammatory drugs; OA: Osteoarthritis; PPAR: Peroxisome proliferator-activated receptor; RA: Rheumatoid arthritis; THC: $\Delta^{9}$ tetrahydrocannabinol; YLD: Years lived with disability.}

\section{Competing interests}

The authors declare no competing interests. The authors do not have any commercial or collaborative relationships that could be construed as biased or inappropriate. The decision to submit the paper for publication was not influenced by any funding body.

Authors' contributions

All authors contributed to drafting of the manuscript. All authors read and approved the final manuscript.

Authors' information

AM and RBJ are members of the D-BOARD European Consortium for Biomarker Discovery

http://www.d-board.eu/dboard/index.aspx

http://cordis.europa.eu/projects/rcn/105314_en.html http://ec.europa.eu/research/health/medical-research/severe-chronicdiseases/projects/d-board_en.html 


\section{Acknowledgements}

The research leading to these results has received partial funding from the European Union Seventh Framework Programme (FP7/2007-2013) under grant agreement number 305815 .

\section{Author details}

'Department of Musculoskeletal Biology, Institute of Ageing and Chronic Disease, University of Liverpool, Liverpool L69 3GA, United Kingdom. ${ }^{2}$ The D-BOARD European Consortium for Biomarker Discovery, School of Veterinary Medicine, Faculty of Health and Medical Sciences, University of Surrey, Duke of Kent Building, Guildford, Surrey GU2 7XH, UK. ${ }^{3}$ Center of Excellence in Genomic Medicine Research (CEGMR), King Fahd Medical Research Center (KFMRC), King Abdul Aziz University, Jeddah 21589, Kingdom of Saudi Arabia. ${ }^{4}$ School of Veterinary Medicine, Faculty of Health and Medical Sciences, University of Surrey, Duke of Kent Building, Guildford, Surrey GU2 7XH, UK. ${ }^{5}$ Arthritis Research UK Centre for Sport, Exercise and Osteoarthritis, Arthritis Research UK Pain Centre, Medical Research Council and Arthritis Research UK Centre for Musculoskeletal Ageing Research, University of Nottingham, Queen's Medical Centre, Nottingham NG7 2UH, UK.

Received: 15 October 2014 Accepted: 25 November 2014 Published: 4 December 2014

\section{References}

1. Munro S, Thomas KL, Abu-Shaar M: Molecular characterization of a peripheral receptor for cannabinoids. Nature 1993, 365:61-65.

2. Howlett AC: Pharmacology of cannabinoid receptors. Annu Rev Pharmacol Toxicol 1995, 35:607-634

3. Ryberg E, Larsson N, Sjogren S, Hjorth S, Hermansson NO, Leonova J, Elebring T, Nilsson K, Drmota T, Geasley PJ: The orphan receptor GPR55 is a novel cannabinoid receptor. Br J Pharmacol 2007, 152:1092-1101.

4. Console-Bram L, Brailoiu E, Brailoiu GC, Sharir H, Abood ME: Activation of GPR18 by cannabinoid compounds: a tale of biased agonism. Br J Pharmacol 2014, 171:3908-3917.

5. Brown AJ: Novel cannabinoid receptors. Br J Pharmacol 2007, 152:567-575.

6. Price MR, Baillie GL, Thomas A, Stevenson LA, Easson M, Goodwin R, McLean A, Mclntosh L, Goodwin G, Walker G, Westwood P, Marrs J, Thomson F, Cowley P, Christopoulos A, Pertwee RG, Ross RA: Allosteric modulation of the cannabinoid CB1 receptor. Mol Pharmacol 2005 68:1484-1495.

7. McPartland JM, Duncan M, Di Marzo V, Pertwee R: Are cannabidiol and delta -tetrahydrocannabivarin negative modulators of the endocannabinoid system? A systematic review. Br J Pharmacol 2014. Epub Ahead of Print doi:10.1111/bph.12944.

8. Tsou K, Brown S, Sanudo-Pena MC, Mackie K, Walker JM: Immunohistochemical distribution of cannabinoid CB1 receptors in the rat central nervous system. Neuroscience 1998, 83:393-411.

9. Stella N: Endocannabinoid signaling in microglial cells. Neuropharmacology 2009, 56(Suppl 1):244-253.

10. Nisen PD, Zimmerman KA, Cotter SV, Gilbert F, Alt FW: Enhanced expression of the N-myc gene in Wilms' tumors. Cancer Res 1986 46:6217-6222.

11. Walter L, Franklin A, Witting A, Wade C, Xie Y, Kunos G, Mackie K, Stella N: Nonpsychotropic cannabinoid receptors regulate microglial cell migration. J Neurosci 2003, 23:1398-1405.

12. Bottini N, Firestein GS: Duality of fibroblast-like synoviocytes in RA: passive responders and imprinted aggressors. Nat Rev Rheumatol 2013, 9:24-33.

13. Sutton S, Clutterbuck A, Harris P, Gent T, Freeman S, Foster N, Barrett-Jolley R, Mobasheri A: The contribution of the synovium, synovial derived inflammatory cytokines and neuropeptides to the pathogenesis of osteoarthritis. Vet J 2009, 179:10-24.

14. Staunton CA, Lewis R, Barrett-Jolley R: Ion channels and osteoarthritic pain: potential for novel analgesics. Curr Pain Headache Rep 2013, 17:1-9.

15. Lee H-R, Park KM, Joung YK, Park KD, Do SH: Platelet-rich plasma loaded hydrogel scaffold enhances chondrogenic differentiation and maturation with up-regulation of CB1 and CB2. J Control Release 2012, 159:332-337.

16. Huffman JW, Liddle J, Yu S, Aung MM, Abood ME, Wiley JL, Martin BR: 3-(1',1'-Dimethylbutyl)-1-deoxy-delta8-THC and related compounds: synthesis of selective ligands for the CB2 receptor. Bioorg Med Chem 1999, 7:2905-2914.
17. Fukuda S, Kohsaka H, Takayasu A, Yokoyama W, Miyabe C, Miyabe Y, Harigai M, Miyasaka N, Nanki T: Cannabinoid receptor 2 as a potential therapeutic target in rheumatoid arthritis. BMC Musculoskelet Disord 2014, 15:275.

18. Cross M, Smith E, Hoy D, Carmona L, Wolfe F, Vos T, Williams B, Gabriel S, Lassere M, Johns N, Buchbinder R, Woolf A, March L: The global burden of rheumatoid arthritis: estimates from the global burden of disease 2010 study. Ann Rheum Dis 2014, 73:1316-1322

19. Reginster JY, Khaltaev NG: Introduction and WHO perspective on the global burden of musculoskeletal conditions. Rheumato/ 2002, 41(Supp 1):1-2.

20. Hoy DG, Smith E, Cross M, Sanchez-Riera L, Blyth FM, Buchbinder R, Woolf AD, Driscoll T, Brooks P, March LM: Reflecting on the global burden of musculoskeletal conditions: lessons learnt from the global burden of disease 2010 study and the next steps forward. Ann Rheum Dis 2014, 1-4. doi:10.1136/annrheumdis-2014-205393.

21. Scanzello CR, Goldring SR: The role of synovitis in osteoarthritis pathogenesis. Bone 2012, 51:249-257.

22. Sellam J, Berenbaum F: The role of synovitis in pathophysiology and clinical symptoms of osteoarthritis. Nat Rev Rheumatol 2010, 6:625-635.

23. Lefevre S, Knedla A, Tennie C, Kampmann A, Wunrau C, Dinser R, Korb A Schnaker E-M, Tarner IH, Robbins PD, Evans CH, Stürz H, Steinmeyer J, Gay S, Schölmerich J, Pap T, Müller-Ladner U, Neumann E: Synovial fibroblasts spread rheumatoid arthritis to unaffected joints. Nat Med 2009, 15:1414-1420.

24. Pap T, Muller-Ladner U, Gay RE, Gay S: Fibroblast biology: role of synovial fibroblasts in the pathogenesis of rheumatoid arthritis. Arthritis Res 2000, 2:361-367.

25. Berenbaum F: Osteoarthritis as an inflammatory disease (osteoarthritis is not osteoarthrosis!). Osteoarthr Cart 2013, 21:16-21.

26. Mobasheri A: The future of osteoarthritis therapeutics: emerging biological therapy. Cur Rheumatol Rep 2013, 15:1-9.

27. Lane NE, Schnitzer TJ, Birbara CA, Mokhtarani M, Shelton DL, Smith MD, Brown MT: Tanezumab for the treatment of pain from osteoarthritis of the knee. N Engl J Med 2010, 363:1521-1531.

28. Barrett-Jolley R, Lewis R, Fallman R, Mobasheri A: The emerging chondrocyte channelome. Front Physiol 2010, 1:1-11

29. Gallagher J, Howlin J, McCarthy C, Murphy EP, Bresnihan B, FitzGerald O, Godson C, Brady HR, Martin F: Identification of Naf1/ABIN-1 among TNF-ainduced expressed genes in human synoviocytes using oligonucleotide microarrays. FEBS Lett 2003, 551:8-12.

30. Byron CR, Barger AM, Stewart AA, Pondenis HC, Fan TM: In vitro expression of receptor activator of nuclear factor-kappaB ligand and osteoprotegerin in cultured equine articular cells. Am J Vet Res 2010, 71:615-622

31. Hardy RS, Hulso C, Liu Y, Gasparini SJ, Fong-Yee C, Tu J, Stoner S, Stewart PM, Raza K, Cooper MS, Seibel MJ, Zhou H: Characterisation of fibroblast-like synoviocytes from a murine model of joint inflammation. Arthritis Res Ther 2013, 15:R24.

32. Zychowska M, Rojewska E, Kreiner G, Nalepa I, Przewlocka B, Mika J: Minocycline influences the anti-inflammatory interleukins and enhances the effectiveness of morphine under mice diabetic neuropathy. J Neuroimmunol 2013, 262:35-45.

33. Alvarez $P$, Levine JD: Screening the role of pronociceptive molecules in a rodent model of endometriosis pain. J Pain 2014, 15:726-733.

34. Moore BA, Aznavoorian S, Engler JA, Windsor LJ: Induction of collagenase-3 (MMP-13) in rheumatoid arthritis synovial fibroblasts. Biochim Biophys Acta 2000, 1502:307-318.

35. Cagnard N, Letourneur F, Essabbani A, Devauchelle V, Mistou S, Rapinat A, Decraene C, Fournier C, Chiocchia G: Interleukin-32, CCL2, PF4F1 and GFD10 are the only cytokine/chemokine genes differentially expressed by in vitro cultured rheumatoid and osteoarthritis fibroblast-like synoviocytes. Eur Cytokine Netw 2005, 16:289-292.

36. Tat SK, Pelletier JP, Velasco CR, Padrines M, Martel-Pelletier J: New perspective in osteoarthritis: the OPG and RANKL system as a potential therapeutic target? Keio J Med 2009, 58:29-40.

37. Ofek O, Karsak M, Leclerc N, Fogel M, Frenkel B, Wright K, Tam J, Attar-Namdar M, Kram V, Shohami E, Mechoulam R, Zimmer A, Bab I: Peripheral cannabinoid receptor, CB2, regulates bone mass. PNAS 2006, 103:696-701.

38. Burston JJ, Sagar DR, Shao P, Bai M, King E, Brailsford L, Turner JM, Hathway GJ, Bennett AJ, Walsh DA, Kendall DA, Lichtman A, Chapman V: Cannabinoid $\mathrm{CB} 2$ receptors regulate central sensitization and pain 
responses associated with osteoarthritis of the knee joint. PLoS One 2013, 8:e80440.

39. De Petrocellis L, Ligresti A, Moriello AS, Allarà M, Bisogno T, Petrosino $S$, Stott CG, Di Marzo V: Effects of cannabinoids and cannabinoid-enriched Cannabis extracts on TRP channels and endocannabinoid metabolic enzymes. Br J Pharmacol 2011, 163:1479-1494.

doi:10.1186/1471-2474-15-410

Cite this article as: Staunton et al:: High hopes for cannabinoid agonists in the treatment of rheumatic diseases. BMC Musculoskeletal Disorders 2014 15:410

\section{Submit your next manuscript to BioMed Central and take full advantage of:}

- Convenient online submission

- Thorough peer review

- No space constraints or color figure charges

- Immediate publication on acceptance

- Inclusion in PubMed, CAS, Scopus and Google Scholar

- Research which is freely available for redistribution 